\title{
Difficulties in diagnosing urinary tract infections in small children
}

\author{
Kjell Tullus
}

Received: 19 April 2011 /Revised: 22 June 2011 /Accepted: 24 June 2011 /Published online: 20 July 2011

(C) IPNA 2011

\begin{abstract}
Urinary tract infections (UTIs) in children appear to be simple and straightforward matters, but there is as yet no consensus on UTIs in this patient group, and it remains one of the most - if not the most - controversial fields in paediatric medicine. Controversy and the lack of consensus can be found in many areas, including the diagnosis and management of UTIs in paediatric patients. Consequently, children with a UTI are investigated and treated quite differently in different parts of the world and also within different parts of the same country. One factor contributing to the current situation is the unexpected difficulty in diagnosing a UTI in children. This difficulty has implications not only for clinical work but also for scientific studies. Substantial over- and under-diagnosing can result from practical difficulties in at least three areas, including problems with collecting urine samples, in interpreting bacterial numbers correctly, and in confusing infantile asymptomatic bacteriuria and a true symptomatic febrile UTI. In this review, these problems will be discussed in detail as well as the implications they have had on clinical practice and research on UTIs.
\end{abstract}

Keywords urine tract infection - bacterial numbers . contamination $\cdot$ asymptomatic bacteriuria

\section{Introduction}

On the face of it, urinary tract infections (UTI) in children seem to be a simple and straightforward matter,

\section{K. Tullus $(\bowtie)$}

Great Ormond Street Hospital for Children,

Great Ormond Street,

London, UK

e-mail: tulluk@gosh.nhs.uk and yet the treatment of UTI is one of the most-if not the most - controversial areas of paediatric medicine. As an example, the recent UK guidelines from NICE (National Institute of Health and Clinical Excellence) were greeted in very different ways. In the UK itself, one response was "Nasty processes produce Nasty guidelines" [1], while in Sweden, the response was "English guidelines-nothing for children with urinary tract infections in Sweden" [2]. A recent report from Australia did, however, give a very different opinion "in Australia at least, it may be a case of guidelines catching up with changes in clinical practice rather than the other way" [3].

These controversies are reflected in many ways, one of which is the large variation in the number and types of follow-up investigations children receive after a UTI. A comparison between 25 children's hospital in the USA showed that between a few percent up to $75 \%$ of children had an micturating cystourethrogram (MCUG) after their UTI [4]. Similarly, in a survey of 23 different American hospitals, the "typical" patient, a 6-year-old girl with private insurance and low disease severity, had a very variable chance to be treated with endoscopic injection, namely, between 7 and $85 \%$ depending on the choice of hospital [5].

How can this be? Children with UTI are very common, and there has been plenty of opportunity to study them and to come to conclusions upon which most paediatricians could agree. However, such a consensus has not seemed to have been reached. The most important disagreements surround the care of younger children with UTI. Here, I discuss a number of important issues regarding the diagnosis of a UTI, with a specific focus on bacteriuria, which I suggest should be given more attention when future studies are being designed. 


\section{Bacterial cultures}

Bacterial numbers of $10^{5}$ colony-forming units $(\mathrm{CFU}) / \mathrm{ml}$ or more are normally regarded as significant growth. This cut-off point dates back to a few papers by Ed Kass in the 1950s who defined a level of bacterial count that would include most patients with true UTI without including too many without a true infection. In his initial publication, however, he acknowledged that the proposed cut-off would lead to a number of false negative diagnoses [6].

Anecdotal data from case series have suggested that a proportion of children with true infections have urine cultures with fewer than $10^{5}$ bacteria [7]. A large population-based study from Sweden found that $73(20 \%)$ of 366 infants with a symptomatic UTI had colony counts of $<10^{5} \mathrm{CFU} / \mathrm{ml}$ [8] based on cultured urine specimens obtained by suprapubic aspiration (SPA). A Finnish study in 477 infants found bacteria in urine specimens collected by SPA in 322 infants, and of these only $81 \%$ showed $>10^{5} \mathrm{CFU} / \mathrm{ml}$ in a clean voided urine specimen [9]. Bacterial numbers in the $19 \%$ of children who would have been missed on the basis of the clean voided specimen ranged from $10^{4}$ (18 children) to $10^{3}$ (20 children) CFU/ml.

It is well established that different cut-off levels are used for bag cultures, SPAs and cultures from catherised samples. This is not very logical in the biological sense as there is no scientific evidence demonstrating that bacteria will have grown exponentially during their transport through the urethra. The different cut-off levels have been decided upon based on the risk of contamination of the bag cultures.

A recent study that used different cut-off levels for bag samples $\left(\geq 10^{6}\right)$ and catheter samples $\left(\geq 10^{3}\right)$ found that there were $29 \%$ false negative bag cultures compared to the catheter samples [10]. Children with true infections can thus be missed both in clinical practice and in scientific studies.

\section{Contaminated cultures}

Contaminated cultures can be quite a substantial problemparticularly in small children. This was emphasised as early as in studies carried out in the 1970s. A study involving 120 infants and children showed a $25 \%$ contamination rate with samples from clear-voided urine compared to samples from suprapubic aspiration [11]. Investigators from the Royal Free Hospital in London also emphasised that a true single organism growth could be hidden in mixed growth from a bag or clean catch sample [12]. A number of subsequent studies have reported quite varying contamination rates. $\mathrm{Al}$ Orifi et al. reported $62.8 \%$ false positive cultures [13], while a recent study reported a $7.5 \%$ contamination rate [10].

This high risk for contaminated cultures is very easy to understand when you know how small children pass urine.
Small boys do regularly flush their prepuce and small girls do regularly flush their vagina (Figs. 1,2). Consequently, it is very difficult to collect a clean urine sample outside of the body of small children.

\section{Asymptomatic bacteriuria}

Asymptomatic bacteriuria (ABU) is quite a common, but not always well recognised, and therefore represents a further complication to making the correct diagnosis of a symptomatic UTI. This is particularly true in infants. Few studies have systematically examined this aspect of pediatric nephrology, but one very well performed Swedish study from 1990 cultured specimens from all 3581 infants born during 1 year in one specific catchment area of Gothenburg. All infants had bag urine cultures performed at 2 weeks, 3 months and 10 months of age. Positive cultures were always confirmed with a culture of urine collected by a supra-pubic bladder puncture [14].

A minimum of $2.5 \%$ of the boys and $0.9 \%$ of the girls showed signs of $\mathrm{ABU}$ during their first year of life (Figs. 3, 4). In the same cohort of children, another $1.2 \%$ of the boys and $1.1 \%$ of the girls developed an episode of febrile symptomatic UTI. Follow-up studies showed that the ABU lasted between 0.5 and 7.5 months (median of 2 and 1.5 months for the girls and boys, respectively) and had resolved spontaneously without any signs of kidney scarring by the 6-year follow-up [14-16]. A subsequent Turkish study which only used clean catch cultures, without confirmation on urine collected by SPA, showed a prevalence of bacteriuria in $4 \%$ of newborns and $5.2 \%$ of infants [17].

\section{Consequences of the difficult diagnosis of febrile UTI}

An infant with $\mathrm{ABU}$ (in nearly all cases not previously diagnosed) will pose a major diagnostic challenge when he/she develops fever from a normal viral disease. It will

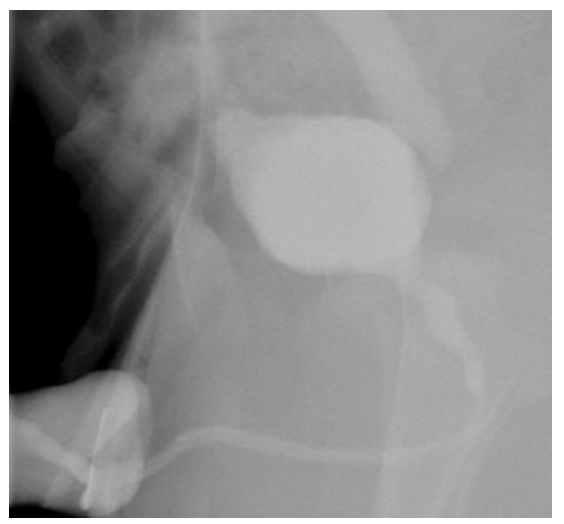

Fig. 1 Micturition cystourethrogram in an infant boy showing the flushing of his prepuce 


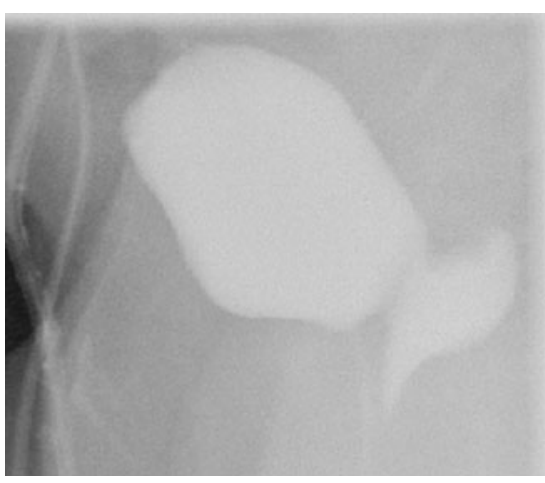

Fig. 2 Micturition cystourethrogram in an infant girl showing the flushing of her vagina

be virtually impossible to dismiss the leucocyturia and bacteriuria as ABU. The child will have to be treated and followed-up as a case of febrile UTI.

Based on the epidemiology data described above, one out of every four infant boys and one out of every six infant girls with true bacteriuria and fever will actually have ABU and/or another infection but be wrongly be diagnosed as a patient with febrile UTI. The chance of contaminated cultures will increase the number of false positive diagnosis to between 7.5 and $62.8 \%$ if SPA cultures are not used to verify the diagnosis.

These potential discrepancies can help to explain the sometimes confusing data that exist regarding different aspects of febrile UTI in children. One such confusing factor is the biologically unlikely finding that the number of

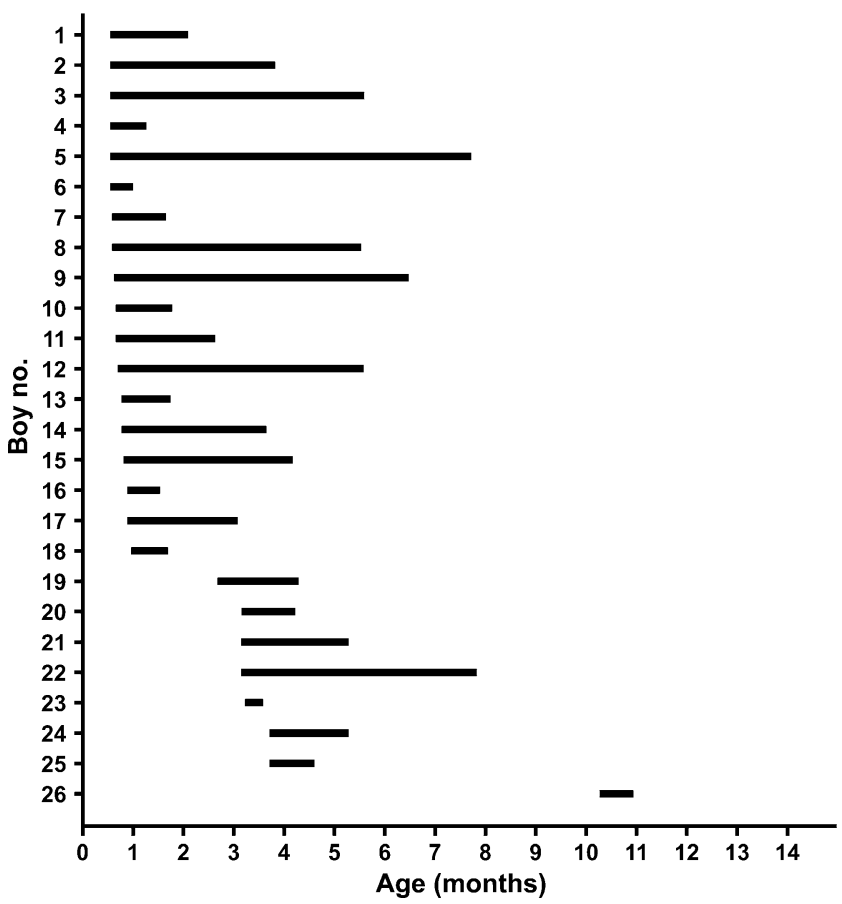

Fig. 3 Asymptomatic bacteriuria in infant boys verified by suprapubic aspiration

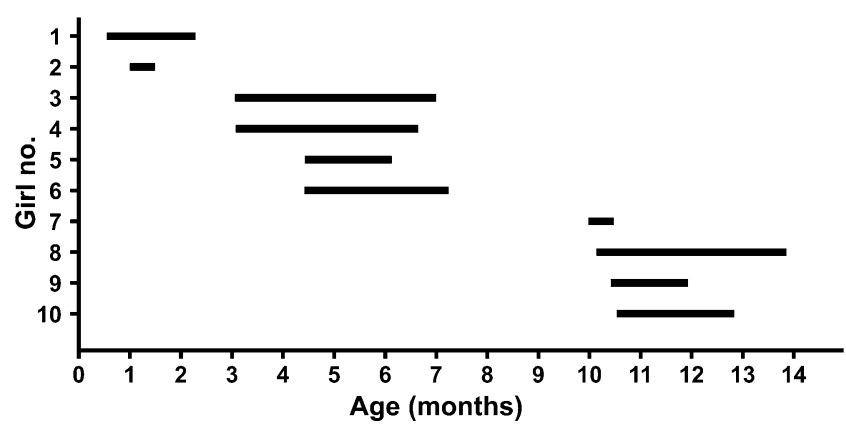

Fig. 4 Asymptomatic bacteriuria in infant girls verified by suprapubic aspiration

infants with proven kidney involvement by an uptake defect, based on the results of dimercaptosuccinic acid (DMSA) scanning in most studies, is lowest in the youngest age group. One study found that only $49 \%$ of infants diagnosed with a febrile UTI showed an uptake defect in at least one kidney compared to $73 \%$ in children between 1 and 4 years and $81 \%$ in children $>5$ years [18]. The rate of scarring defined as an uptake defect on the 6-month DMSA scan was also lower among the infants: 28 vs. 37 and 53\% in the two older age groups, respectively.

The results of studies in infantile febrile UTI run the risk of being diluted and sometimes difficult to use because of the children with false positive diagnosis. This is true for studies such as those on inflammatory markers and the rate of vesicoureteric reflux. Six studies have recently been published on antimicrobial prophylaxis for the prevention of recurrent UTI in infants and children with vesicoureteric reflux [19-24]. Three of these studies used mainly suprapubic aspiration or bladder catherisation [19-21], while the others relied on bag collection of urine [22-24]. A difference in the rate of recurrent UTI between the children receiving antibiotics and the children who did not was found only in two of the studies that used the more accurate urine collection methods $[19,20]$. It is known that enrolling children in a study who are not correctly diagnosed, possibly due to a contaminated urine test, can dilute the study results and give a false negative study result.

\section{What should be done when planning further studies?}

The most accurate method possible to collect urine in each age group should be used. In studies of febrile UTI, several different measurements of systemic inflammation, including C-reactive protein and procalcitonin, should be performed in all children. If children with low CRP and procalcitonin values are included in the study, then data should be presented for both groups of children.

Children with a pure growth of bacteria in the urine, but with bacterial numbers below the cut-off levels that are 
normally used, for whom other clinical criteria from the urine test support a diagnosis of a UTI should not be excluded from the study but be presented as a separate arm. Circumcision greatly reduces both the risk for recurrent UTI and for preputial contamination, and the results should thus be presented separately for boys who are not circumcised and those who are.

Alternative diagnoses should not be excluded, particularly in febrile infants. A search for respiratory viruses as a possible cause of the increased temperature and leucocyturia should be performed with PCR. Such testing will help to distinguish children with fever and asymptomatic bacteriuria (ABU) from children with a true febrile UTI.

In clinical practice and in clinical studies, there will always be a number of children for whom it is not possible to obtain optimal urine cultures or to perform all relevant additional diagnostic tests. Analysing the data separately for children with and without optimal diagnostic studies can be one way to further our understanding of these issues.

In summary, there are several reasons why scientific and clinical knowledge on infantile febrile UTI is still so confusing. These include both false negative and positive diagnoses due to contamination of the specimen, other febrile infections in children with pre-existing asymptomatic bacteriuria and problems arising from which bacterial number constitutes a "true" UTI. Further studies to clarify the treatment management of children with a UTI will need to take the issues discussed above into consideration.

\section{Reference}

1. Coulthard MG (2007) NICE on childhood UTI: Nasty processes produce nasty guidelines. Br Med J 335:463-464

2. Jodal U, Hansson S, Swerkersson S, Berg UB, Herthelius M, Storby KA (2008) English guidelines-nothing for children with urinary infections in Sweden. Lakartidningen 105:1753-1756

3. South M (2009) Radiological investigations following urinary tract infection: changes in Australian practice. Arch Dis Child 94:927-930

4. Conway PH, Keren R (2009) Factors associated with variability in outcomes for children hospitalized with urinary tract infection. $\mathrm{J}$ Pediatr 154:789-796

5. Routh JC, Nelson CP, Graham DA, Lieu TA (2010) Variation in surgical management of vesicoureteral reflux: influence of hospital and patient factors. Pediatrics 125:e446-e451

6. MacDonald RA, Levitin H, Mallory K, Kass EH (1957) Relation between pyelonephritis and bacterial counts in the urine. New Engl J Med 256:915-922

7. Bollgren I, Engstrom CF, Hammarlind M, Kallenius G, Ringertz H, Svenson SB (1984) Low urinary counts of P-fimbriated Escherichia coli in presumed acute pyelonephritis. Arch Dis Child 59:102-106

8. Hansson S, Brandstrom P, Jodal U, Larsson P (1998) Low bacterial counts in infants with urinary tract infection. J Pediatr 132:180-182
9. Koskimies O (1995) Diagnostic accuracy of urinary tract infection and subsequent development of renal scars. J Pediatr 126:157-159

10. Etoubleau C, Reveret M, Brouet D, Badier I, Brosset P, Fourcade L, Bahans C, Garnier F, Blanc P, Guigonis V (2009) Moving from bag to catheter for urine collection in non-toilet-trained children suspected of having urinary tract infection: a paired comparison of urine cultures. J Pediatr 154:803-806

11. Aronson AS, Gustafson B, Svenningsen NW (1973) Combined suprapubic aspiration and clean-voided urine examination in infants and children. Acta Paediatr Scand 62:396-400

12. Hardy JD, Furnell PM, Brumfitt W (1976) Comparison of sterile bag, clean catch and suprapubic aspiration in the diagnosis of urinary infection in early childhood. Br J Urol 48:279-283

13. Al-Orifi F, McGillivray D, Tange S, Kramer MS (2000) Urine culture from bag specimens in young children: are the risks too high? J Pediatr 137:221-226

14. Wettergren B, Jodal U (1990) Spontaneous clearance of asymptomatic bacteriuria in infants. Acta Paediatr Scand 79:300-304

15. Wettergren B, Jodal U, Jonasson G (1985) Epidemiology of bacteriuria during the first year of life. Acta Paediatr Scand 74:925-933

16. Wettergren B, Hellstrom M, Stokland E, Jodal U (1990) Six year follow up of infants with bacteriuria on screening. Br Med J 301:845-848

17. Nebigil I, Tumer N (1992) Asymptomatic urinary tract infection in childhood. Eur J Pediatr 151:308-309

18. Pecile P, Miorin E, Romanello C, Vidal E, Contardo M, Valent F, Tenore A (2009) Age-related renal parenchymal lesions in children with first febrile urinary tract infections. Pediatrics 124:23-29

19. Brandstrom P, Esbjorner E, Herthelius M, Swerkersson S, Jodal U, Hansson S (2010) The Swedish reflux trial in children: III. Urinary tract infection pattern. J Urol 184:286291

20. Craig JC, Simpson JM, Williams GJ, Lowe A, Reynolds GJ, McTaggart SJ, Hodson EM, Carapetis JR, Cranswick NE, Smith G, Irwig LM, Caldwell PH, Hamilton S, Roy LP (2009) Antibiotic prophylaxis and recurrent urinary tract infection in children. $\mathrm{N}$ Engl J Med 361:1748-1759

21. Garin EH, Olavarria F, Garcia NV, Valenciano B, Campos A, Young L (2006) Clinical significance of primary vesicoureteral reflux and urinary antibiotic prophylaxis after acute pyelonephritis: a multicenter, randomized, controlled study. Pediatrics 117:626-632

22. Montini G, Rigon L, Zucchetta P, Fregonese F, Toffolo A, Gobber D, Cecchin D, Pavanello L, Molinari PP, Maschio F, Zanchetta S, Cassar W, Casadio L, Crivellaro C, Fortunati P, Corsini A, Calderan A, Comacchio S, Tommasi L, Hewitt IK, Da DL, Zacchello G, Dall'Amico R (2008) Prophylaxis after first febrile urinary tract infection in children? A multicenter, randomized, controlled, noninferiority trial. Pediatrics 122:1064-1071

23. Pennesi M, Travan L, Peratoner L, Bordugo A, Cattaneo A, Ronfani L, Minisini S, Ventura A (2008) Is antibiotic prophylaxis in children with vesicoureteral reflux effective in preventing pyelonephritis and renal scars? A randomized, controlled trial. Pediatrics 121:e1489-e1494

24. Roussey-Kesler G, Gadjos V, Idres N, Horen B, Ichay L, Leclair MD, Raymond F, Grellier A, Hazart I, de Parscau L, Salomon R, Champion G, Leroy V, Guigonis V, Siret D, Palcoux JB, Taque S, Lemoigne A, Nguyen JM, Guyot C (2008) Antibiotic prophylaxis for the prevention of recurrent urinary tract infection in children with low grade vesicoureteral reflux: results from a prospective randomized study. J Urol 179:674-679 